\title{
LAS AGUAS RESIDUALES REGENERADAS COMO RECURSO PARA LOS REGADÍOS DE LA DEMARCACIÓN HIDROGRÁFICA DEL SEGURA $(\text { ESPAÑA })^{*}$
}

\author{
Alfredo Pérez Morales \\ Encarnación Gil Meseguer \\ José María Gómez Espín \\ Departamento de Geografía. Universidad de Murcia. \\ alfredop@um.es, encargil@um.es, espin@um.es
}

\section{RESUMEN}

En el Sureste de la Península Ibérica, la Demarcación Hidrográfica de Segura presenta un déficit estructural en la relación recursos/demandas de más de $317 \mathrm{hm} / 3 /$ año para el escenario 2015. Esta situación crónica de escasez de agua, así como los compromisos de la aplicación de la Directiva Marco del Agua, obligan a unas iniciativas e inversiones, públicas y privadas, para mejorar la calidad y sostenibilidad del uso del agua. Los planes de saneamiento, las tecnologías del agua, y las medidas para reutilizarla, han permitido recuperar más de $131 \mathrm{hm}^{3} /$ año de aguas residuales, que una vez tratadas y regeneradas, se aplican en asegurar regadíos y en facilitar otros usos como el ambiental en la Cuenca de Segura.

Palabras clave: Sureste de la Península Ibérica, Demarcación Hidrográfica del Segura, depuración, reutilización, aguas residuales regeneradas, regadíos.

Fecha de recepción: febrero 2012.

Fecha de aceptación: julio 2013.

* Esta investigación forma parte del Proyecto CSO2010-19947 «Uso eficiente y sostenible del agua en la Cuenca del Segura: Modernización de regadíos». Ministerio de Ciencia e Innovación. Plan Nacional de I+D+i. Convocatoria 2010 de ayudas de Proyectos de Investigación Fundamental no orientada (BOE 31/12/2009). También del Cluster de Tecnologías del Agua en el Proyecto SWAM Proyect is supported by the European Commission within the scope of the $7^{\text {th }}$ Framework programme «Regions of Knowledge and Research Potential». 


\section{ABSTRACT}

In the southeast of the Iberian Peninsula, the Segura River Basin has a structural deficit in the resources/demands of more than $317 \mathrm{hm}^{3} /$ year for the 2015 scenario. This chronic water shortage and the commitments implementing the Water Framework Directive, require some initiatives and investments, public and private, in order to improve the quality and sustainability of water use. The sewerage plans, water technologies, and measures to reuse, have recovered more than $131 \mathrm{hm}^{3} /$ año wastewater which is treated and then applied to irrigation and ensure other uses such as the environmental in the Segura Basin.

Key words: South-east of the Iberian Peninsula, Hydrographic Demarcation of Segura. treatment, reuse, reclaimed wastewater, irrigation.

\section{INTERÉS GEOGRÁFICO. OBJETO Y MÉTODO}

En los países desarrollados y en desarrollo, la rápida urbanización y la consiguiente creciente demanda de agua potable, para uso industrial y/o agrícola supone un serio inconveniente en aquellos donde los recursos hídricos destacan por su insuficiencia. Estas circunstancias constituyen un serio problema en la Región del Mediterráneo y, sobre todo, en las zonas áridas y semiáridas del Sur y en el Oriente Medio, donde además, no hay que olvidar la cuestión universal de las aguas residuales. Ambas particularidades, carestía y contaminación, han tratado de ser solventadas con más o menos éxito en función de la capacidad de desarrollar estrategias de gestión integral del agua por medio de grandes y costosas infraestructuras.

En lo que se refiere a las actuaciones relacionadas con los usos no convencionales, la tendencia actual parece estar relacionada con la intensificación del reciclaje de aguas residuales. El tratamiento y la reutilización de estos recursos sobresalen en cuanto a sus ventajas económicas y ecológicas frente a la desalación de agua de mar, y, a pesar de la reducción de los costes de esta última tecnología, la diferencia entre las dos soluciones aún se mantiene gracias a los progresos simultáneos del reciclaje (Angelakis, Marecos Do Monte, Bontoux y Asano; 1999).

La Demarcación Hidrográfica del Segura (DHS; SE España) es una de esas cuencas de la región mediterránea que más sufren la escasez de agua. El balance hídrico en la DHS indica que la demanda se encuentra muy por encima de los recursos hídricos disponibles, lo que a las postre acentúa su déficit (Gil, Amorós, y Hernández; 2005). A lo anterior hay que añadirle la probable disminución de dichos recursos en el medio y largo plazo, bien, debido a una disminución de los registros pluviométricos asociada al cambio climático (Giorgi, y Lionello; 2008), o simplemente, por un incremento de las demandas asociadas, principalmente, a la actividad agrícola. Con este panorama de menos y peor agua distribuida, la reutilización de los volúmenes tratados en la DHS es uno de los principales estímulos del plan nacional de gestión de los recursos hídricos para hacer frente a ese problemático escenario, además, es también una parte importante de los criterios de una nueva política ambiental que, de forma conjunta, promueven una nueva cultura del agua, tratando de aumentar el uso no convencional y garantizar al mismo tiempo la física, química, y la calidad bacteriológica de los recursos hídricos (Pérez et al., 2011). 
El objeto de esta investigación es, precisamente, el de tratar de explicar y presentar aquellas iniciativas que, en una cuenca con déficit estructural como la de Segura, se vienen realizando en los últimos años para aportar nuevos recursos procedentes de la reutilización, y cuyo destino final, una vez regenerados ${ }^{1}$, serán mayoritariamente los regadíos del Sureste de la Península Ibérica. La reutilización en la DHS se realiza con una doble finalidad: la de depurar unas aguas que cumplan con unas condiciones de calidad (DMA y Otras recomendaciones) y recuperar como nuevo recurso la mayor parte de las aguas depuradas sometiéndolas a diversos procesos en función de la reutilización que se les va a dar. Los parámetros físico-químicos y microbiológicos de aguas regeneradas para riego son los que aconsejan su uso en cultivos como los frutales de hueso y pepita, incluidos almendro, olivar y viñedo, especialmente con sistemas de riego a presión localizado del tipo goteo (Nicolás et al, 2012). Para poder llevar a cabo esos retornos de agua regenerados es necesaria la depuración, generalmente en las denominadas estaciones de depuración de aguas residuales (EDAR), aplicándoles tratamientos terciarios que mejoren la calidad de las aguas.

Metodológicamente, desde el Análisis Geográfico Regional se aborda el estudio de la distribución geográfica de las EDAR y las tecnologías empleadas para el tratamiento de las aguas residuales, las infraestructuras creadas para llevar estas aguas a los perímetros de riego en los que se desean aplicar y a los cauces naturales a los que se vierten para mejorar su caudal ecológico, así como los paisajes relacionados con estos recursos. También se pretende vislumbrar cómo valoran los regantes estos nuevos recursos y a qué cultivos los aplican a fin de determinar el grado de satisfacción del usuario final.

\section{INTRODUCCIÓN. LA REUTILIZACIÓN DE AGUAS RESIDUALES TRATADAS PARA HACER FRENTE A LA ESCASEZ DE AGUA EN UNA CUENCA COMO LA DEL SEGURA}

La DHS está ubicada en el ámbito del Mediterráneo Occidental, y cuenta con una superficie aproximada de $18.870 \mathrm{~km}^{2}$ que atañen a cuatro comunidades autónomas: prácticamente la totalidad de la Región de Murcia (el 59,02\% de la DHS), parte de la provincia de Albacete (el 25,09\% a Castilla-La Mancha); parcialmente las provincias de Jaén, Granada y Almería (el 9,48\% a Andalucía), y el sector meridional de la provincia de Alicante (el 6,41\% a la Comunidad Valenciana).

En términos oficiales, el Real Decreto 125/2007, de 2 de febrero, por el que se fija el ámbito territorial de las demarcaciones hidrográficas, indica en su artículo $2^{\circ}$ que la DHS «comprende el territorio de las cuencas hidrográficas que vierten al Mar Mediterráneo entre la desembocadura del Río Almanzora y la margen izquierda de la Gola del Segura en su desembocadura, incluidas sus aguas de transición; además de la subcuenca hidrográfica de la Rambla de Canalejas y las cuencas endorreicas de Yecla y Corral Rubio. Las aguas costeras tienen como límite sur la línea con orientación $122^{\circ}$ que pasa por el Puntazo de los Ratones (al norte de la desembocadura del Río Almanzora), y como límite norte la línea de orienta-

1 Se pueden definir las aguas regeneradas como aquellas aguas residuales depuradas que han sido sometidas a un proceso de tratamiento adicional o complementario, que permite adecuar su calidad al uso que se destinan (Albacete, 2009: 12). 
Figura 1

LOCALIZACIÓN DE LA DEMARCACIÓN HIDROGRÁFICA DEL SEGURA EN EL SURESTE DE ESPAÑA Y ESTACIONES DE DEPURACIÓN DE AGUAS RESIDUALES (EDAR) CON SUS VOLÚMENES TRATADOS

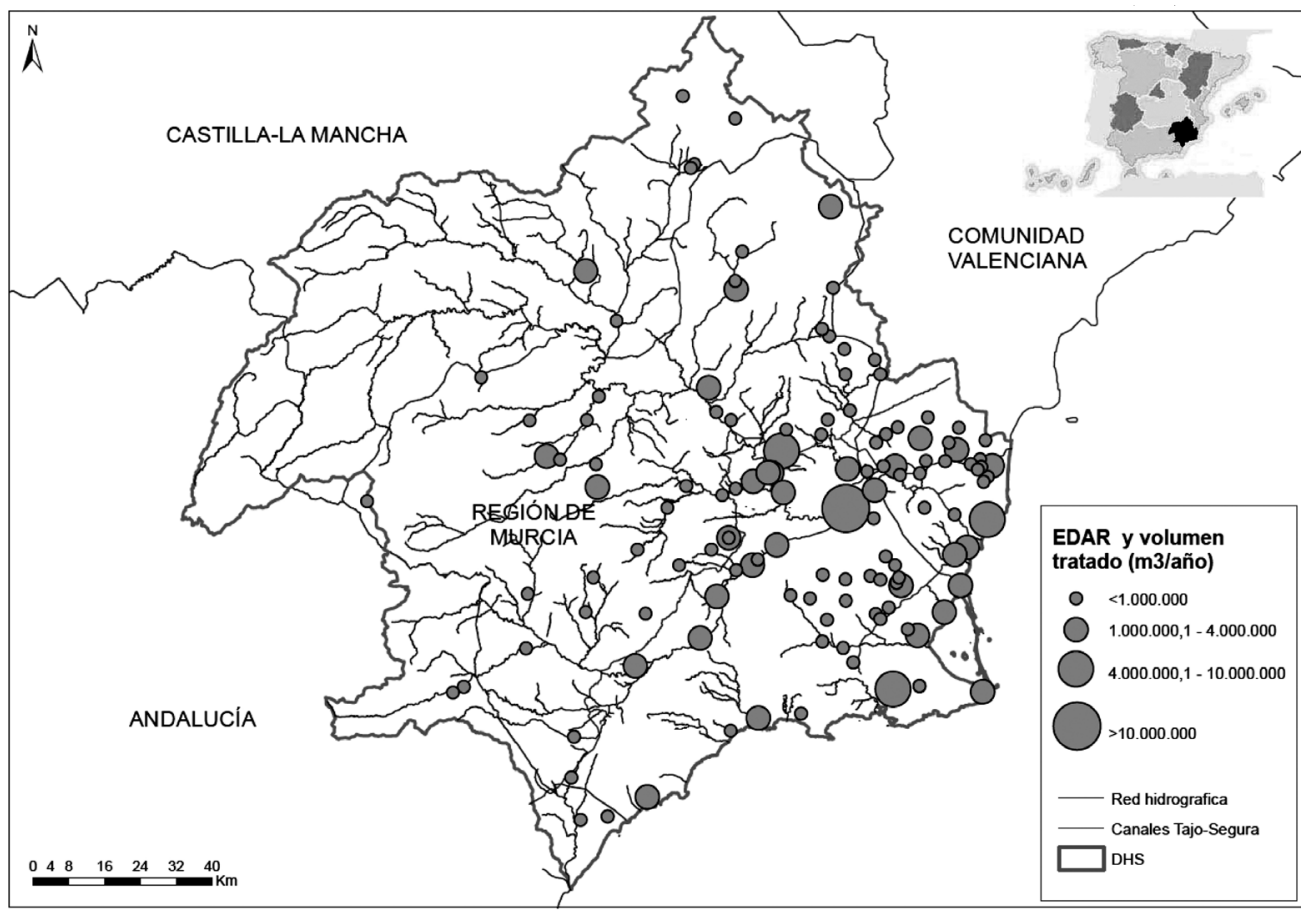

Fuente: Elaboración propia a partir de datos de ESAMUR, EPSAR y CHS (2012).

ción $100^{\circ}$ que pasa por el borde costero entre los términos municipales de Elche y Guardamar del Segura».

El clima presenta un predominio del tiempo seco anticiclónico que unido a la disposición de los relieves Béticos a modo de pantalla deflectora de los vientos del oeste, provoca y acentúa la escasez de precipitaciones sobre el espacio surestino. Asimismo, la posición latitudinal y la baja altitud media de la mayor parte de la DHS propicia una temperatura media superior a $\operatorname{los} 16^{\circ} \mathrm{C}$, lo que unido a la indigencia pluviométrica, especialmente acusada en verano, origina un acusado déficit hídrico en los campos litorales y prelitorales en los que apenas se extendería la vegetación rala de estepa semiárida.

Bajo estas condiciones, la red fluvial del Segura está representada por una red de colectores del tipo rambla o río rambla con reducido o nulo caudal salvo puntuales situaciones asociadas a lluvias de fuerte intensidad horaria. A la escasez de agua se ha respondido con una elevada eficiencia en los casos de abastecimiento y riego, pero también se ha tenido que recurrir a la sobreexplotación de acuíferos, a las transferencias de recursos de otras cuencas (Trasvase Tajo-Segura), a nuevos recursos como los de desalobración y desalación, e incluso, al aprovechamiento de las aguas residuales una vez tratadas en más de 130 Estaciones Depu- 
radoras de Aguas Residuales (EDAR), que se recuperan tras la depuración². Casi la totalidad de estos últimos, se emplean en riego, generalmente mezclados con otros, en los embalses de las distintas comunidades de regantes. El resto, se destinan a uso ambiental como caudal ecológico en algunos tramos del Segura y de sus afluentes.

La mayor parte de los recursos hídricos propios de la Cuenca del Segura, proceden de la cabecera del Segura, (afluentes como el Zumeta, Turrilla, Mundo, Tus, Taibilla, etc.); el resto son cauces caracterizados por sus largos periodos de estiaje y circulación efímera tras lluvias de fuerte intensidad horaria. Por la margen izquierda las ramblas del Judío, Moro, Tinajón, Santomera, etc. y en la derecha, los pequeños ríos-rambla como Alharabe, Moratalla, Argos, Quipar, Mula y Guadalentín o Sangonera. En la DHS también se incluyen las redes de drenaje que vierten a la albufera del Mar Menor como la de El Albujón; las que desembocan en el Mediterráneo como las de Benipila, Las Moreras, El Charcón, etc.; y las áreas endorreicas de Corral Rubio y Yecla, al NE de la Demarcación.

En estas circunstancias de escasez de recursos naturales, el balance hídrico de la DHS es deficitario, lo que provoca que las necesidades de abastecimientos, regadíos y otros usos superen a la suma de volúmenes propios y los trasvasados de otras cuencas. En el Documento Provisional del Esquema de Temas Importantes realizado sobre el ámbito de la DHS, para el horizonte 2015, (http://www.chsegura.es/chs/planificacionydma), figuraba la siguiente estimación: Como recursos totales disponibles existían unos $1432 \mathrm{hm} 3 /$ año (aguas superficiales de la cuenca el 34,56\%; aguas subterráneas el 28,75\%, trasvase Tajo-Segura el 27,91\%, y otros el 8,78\%). Por su lado, las demandas se evaluaban en 1837 hmªño y corresponderían a usos agrarios el $84,35 \%$, a urbano e industrial el $12,92 \%$ y a ambiental el 2,72\%. El déficit por tanto superaba los $300 \mathrm{hm} 3 /$ año y se proponían como medidas para reducirlo, (ante el fracaso de la desalación por los precios para el riego), la práctica de sistemas de riegos deficitarios, intensificar las políticas de modernización de regadíos, y apostar claramente por la reutilización tras la depuración y regeneración adecuada según usos.

2 El objetivo principal de un proceso de depuración de aguas es reducir la carga de contaminantes de la misma y de manera especial la de origen orgánico. De este modo, se consigue que esa agua pueda verterse a un medio receptor natural sin que se produzcan daños ambientales en él. Los porcentajes de eliminación actuales para una planta depuradora convencional se sitúan entre el $90 \%$ y el 95\%, expresado en términos de demanda bioquímica de oxígeno (DBO5), de materia en suspensión y de turbiedad. Los procesos de depuración se estructuran en diferentes niveles en función de tipo de equipos utilizados y sus rendimientos: 1. Pretratamiento. Implica las operaciones de tamizado que consiguen separar los elementos de gran tamaño que entorpecerían el correcto funcionamiento del resto de etapas además de las grasas.

2. Tratamiento primario. Consiste en separar del agua la materia orgánica fácilmente sedimentable por efecto exclusivo de la gravedad. Para llevarlo a cabo, se usan unos depósitos de precipitación llamados decantadores primarios.

3. Tratamiento secundario. El tratamiento secundario consiste en la eliminación de la materia orgánica biodegradable soluble y coloidal y es llevado a cabo por un proceso biológico aerobio en tanques de aireación y gracias a la presencia de microorganismos aerobios en el agua. Estos microorganismos se alimentan de la materia orgánica biodegradable de manera que se reduce su contenido en el agua.

4. Tratamiento terciario. El tratamiento terciario es un proceso de depuración complementario al secundario formado por una coagulación-floculación, una decantación, una filtración y una desinfección. Puede llegar a eliminar una fracción elevada de los virus y las bacterias presentes en el efluente. Además, este proceso de tratamiento reduce la turbiedad del agua residual hasta niveles muy bajos, lo que asegura la eficacia del proceso de desinfección que se efectúa posteriormente. 


\section{EL CICLO DEL AGUA. MARCO CONCEPTUAL Y ADMINISTRATIVO DE LA REUTILIZACIÓN: SANEAMIENTO Y DEPURACIÓN}

Las consideraciones sobre el régimen jurídico del saneamiento de las aguas residuales es uno de los elementos esenciales que reflejan el grado de percepción que las administraciones a las que competen estos asuntos tienen de los mismos. En líneas generales, la evolución seguida por distintos países ha sido bastante desigual, no obstante se advierte una repercusión especial en aquellos donde el problema de la contaminación adquiere tal importancia que se convierte en un asunto de estado ${ }^{3}$. En la Unión Europea y España, el tratamiento recibido por parte de la legislación ha ido experimentando un desarrollo que viene consolidándose desde la última década de los años noventa. Conviene por tanto detenernos en el análisis pormenorizado y razonado de dicha normativa, valorando desde el ámbito supranacional al local.

El marco político-administrativo de la reutilización se organiza jerárquicamente desde la escala europea, a través de la Directiva Comunitaria 91/271/CEE, de 12 de mayo, y de la Directiva Marco del Agua (2000/60/CE); pasando por la nacional del Estado español con la transposición de esas directivas y el Plan Nacional de Calidad de las Aguas; y una dimensión regional, referidas sobre todo al ámbito de la DHS en la Región de Murcia y en la Comunidad Valenciana.

La Directiva 91/271/CEE, sobre el tratamiento de las aguas residuales urbanas, fue la primera norma comunitaria que tuvo por objeto específico regular el saneamiento de las aguas residuales, aunque también es cierto que se habían dictado con anterioridad otras normas que de manera indirecta incidían sobre esta materia. El mencionado documento legal, está dirigido a los Estados miembros, pero en realidad establece obligaciones para los niveles regionales, en una aplicación del principio de subsidiariedad, a los que exige contar con determinados sistemas de recogida y tratamientos de las aguas residuales.

La transposición al derecho interno de este documento legal requería por tanto de una serie de medidas previas que fueron recogidas en el Plan Nacional de Saneamiento y Depuración de Aguas Residuales 1995-2006. En este último se trató de planificar y de minimizar el gran coste económico que suponía la implantación de las normas comunitarias. De haberse completado este plan y depurarse correctamente todos los vertidos urbanos producidos en territorio nacional, se habría podido disponer de un potencial de agua máximo próximo a los 5.000 hm³/año (Rico et al., 1998: 53). Sin embargo, pese a los esfuerzos realizados por el gobierno español desde la transposición de la normativa, no se logró cumplir plena y totalmente con lo exigido por la Directiva 91/271/CEE. Por ello, una vez finalizado el periodo de aplicación del anterior plan, fue necesaria la previsión de otro que permitiera finalizar y cumplir con las exigencias comentadas y también de aquellas otras aprobadas con posterioridad en materia de aguas ${ }^{4}$. Fruto de esta realidad se aprobó por Consejo de Ministros de 8

3 El 29 de septiembre de 2011, el Senado de Méjico aprobó la inserción de un quinto párrafo a la Constitución: «toda persona tiene el derecho al acceso, disposición y saneamiento de agua para consumo personal y doméstico en forma suficiente, salubre, aceptable y asequible. El Estado garantizará este derecho.»

4 La Directiva Marco Europea del Agua (DMA) nace el 22 de Diciembre de 2000 como respuesta a la necesidad de unificar las actuaciones en materia de gestión de agua en los países miembros de la Unión Europea. Debido a que las aguas de la Comunidad Europea están sometidas a la creciente presión que supone el continuo crecimiento 


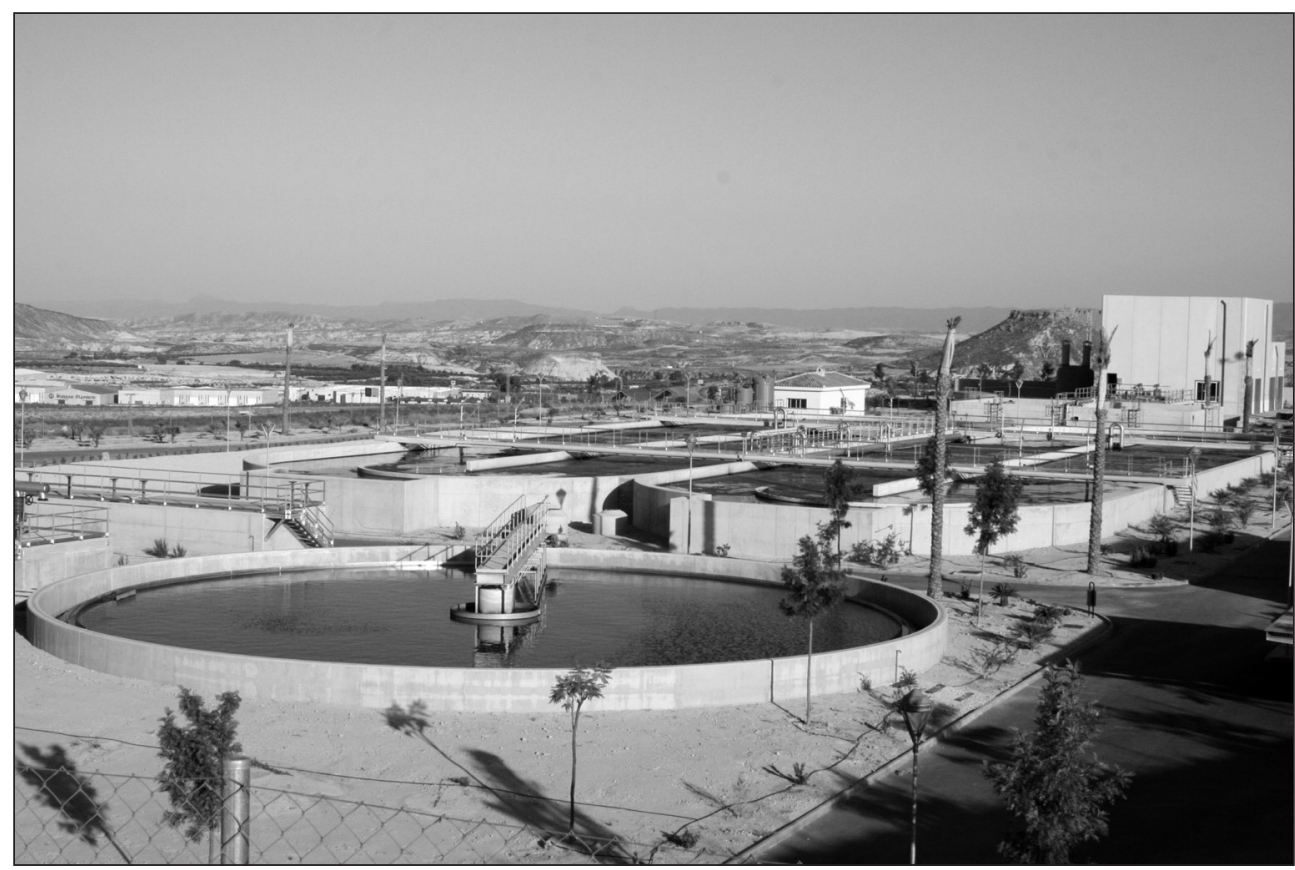

Fuente: Autores.

de junio de 2007 las bases del nuevo Plan Nacional de Calidad de las Aguas: Saneamiento y Depuración 2007-2015, cuyos objetivos eran, principalmente, terminar todo lo pendiente y contribuir a alcanzar en el año 2015 los objetivos medioambientales establecidos en la Directiva Marco del Agua 2000/60/CE, (Oller, 2008: 164-167). En el año 2012, las CC.AA. que habían culminado dicha tarea eran: Región de Murcia, La Rioja, Navarra y Madrid.

A nivel del Estado, el Plan Nacional de Calidad de las Aguas (2007-2015) tiene previstas varias inversiones en el Sureste de España, ámbito de la DHS, con objeto de mejorar la calidad de las aguas. Entre las actuaciones financiadas sobresalen: La ampliación de la Estación Depuradora de Aguas Residuales (EDAR) de Hellín y la de la EDAR Murcia-Este; ambas declaradas de interés general (más de 170 millones de euros de inversión). Otras EDAR de menor capacidad y tamaño (con unos 450 millones de inversión) para las de Tobarra, Ontur y Montealegre del Castillo en Albacete; las de Alguazas, Fuente-Álamo, Puerto Lumbreras y Cehegín en Murcia; y la de Rojales en Alicante. Además contempla el aprovechamiento de aguas pluviales mediante la creación de tanques de tormentas (unos 208 millones de euros de inversión). 
En la Región de Murcia, la Ley 3/2000 de 12 de julio, de Saneamiento y Depuración de Aguas Residuales (LSD), diseñó un nuevo sistema de gestión para las aguas residuales. Con un Plan General de Saneamiento y Depuración, un Ente Público como la Entidad de Saneamiento (ESAMUR), y un instrumento financiero como el canon de saneamiento, que ha permitido el correcto funcionamiento y control de las depuradoras y de los sistemas generales de colectores de aguas residuales. En la Exposición de motivos de este plan, se resalta el papel de los recursos de agua en un cuenca deficitaria como la del Segura: «El agua es el recurso natural más escaso en la Región de Murcia y su búsqueda constituye un afán permanente en la historia de su territorio donde la vida y la actividad socioeconómica han dependido siempre de su disponibilidad. Por ello, la Cuenca del río Segura, donde se ubica casi toda esta Región, es un mosaico de obras hidráulicas que testimonian la forma con que las culturas mediterráneas se aproximaron al déficit hídrico que afecta a esta parte de la Península Ibérica...» (Real Academia de Legislación y Jurisprudencia de Murcia, 2001: 7).

El desarrollo del Plan de Saneamiento y Depuración (2001-2010) ha logrado que el $99,0 \%$ de la población cuente con recogida y tratamiento de sus aguas residuales. El parque de infraestructuras de saneamiento que controla ESAMUR (Entidad de Saneamiento y Depuración de Aguas Residuales de la Región de Murcia) mantiene y explota 88 EDAR, de las que el 57,5\% son de depuración biológica, el 40,3\% de depuración biológica con tratamiento terciario y el 2,1\% de plantas de lagunaje. También gestiona 42 Estaciones de Bombeo de Aguas Residuales, como la de Murcia-Margen Izquierda. La implantación del canon de saneamiento permite el mantenimiento de todas estas infraestructuras; en el año 2012 un usuario doméstico de la ciudad de Murcia debía pagar $32 € / a n ̃ o$ de cuota de servicio y $0,27 € /$ metro cúbico de cuota de consumo. En los últimos años se realiza un control de vertidos industriales en las empresas potencialmente contaminantes, (a través de inspecciones y toma de muestras), aplicando el principio de «quien contamina paga» y un corrector de la tarifa del canon de saneamiento para evitar efectos negativos o sobrecostes innecesarios en las EDAR. La industria conectada al alcantarillado, en su mayor parte agroalimentaria, ha realizado también un notable esfuerzo para hacer compatibles unos vertidos con los tratamientos de las EDAR, y ya en el año 2012, contaba con una capacidad de depuración en origen próxima a $20.000 \mathrm{~m}^{3} /$ día.

Posteriormente, la promulgación del Real Decreto 1620/2007, que regulaba las condiciones para la reutilización de las aguas depuradas, planteaba mayores exigencias en los tratamientos terciarios para las aguas regeneradas. En el caso de la Región de Murcia se han aplicado tratamientos físico-químicos, filtración, desinfección y la tecnología más reciente de ultrafiltración o microfiltración mediante membranas, que hace que la eliminación de bacterias patógenas sea prácticamente total. (Albacete, 2009: 7).

La Consejería de Agricultura y Agua de la Comunidad Autónoma de la Región de Murcia (CARM), para facilitar que las aguas depuradas y regeneradas para el riego puedan ser usadas por las distintas asociaciones y comunidades de regantes que tienen concedidas estas aguas por la Confederación Hidrográfica del Segura, publicó la Orden de 18 de febrero de 2008 , con objeto de ayudar a la financiación de hasta el $70 \%$ de las inversiones necesarias para llevar a cabo las obras de regulación, transporte y acondicionamiento desde las EDAR a las zonas regables. Convocatoria de ayudas que se ha realizado también en años posteriores, acogiéndose casi una veintena de estas entidades. 


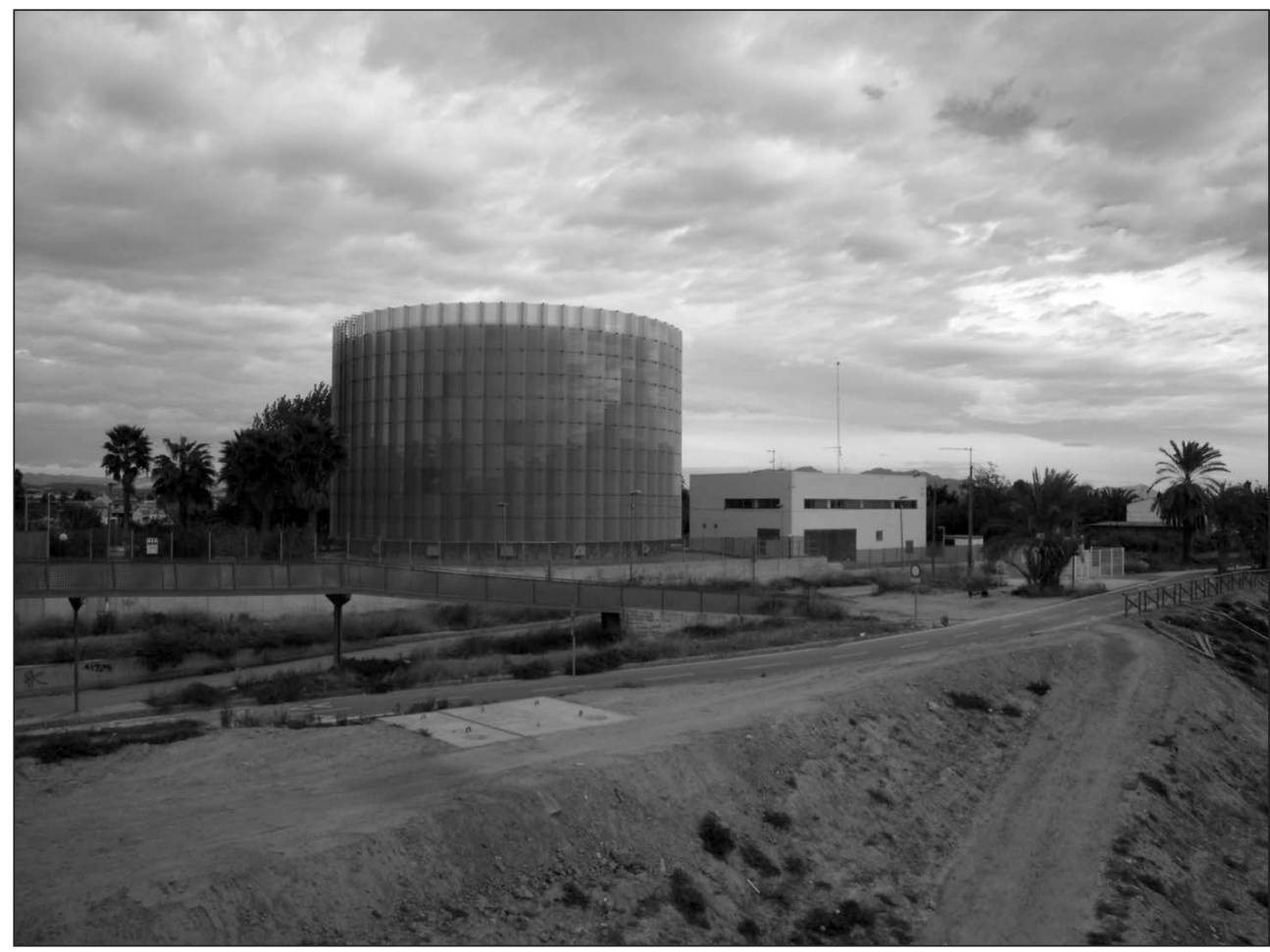

Fuente: Autores.

Finalmente, en la provincia de Alicante, la normativa reguladora arranca de la Ley 2/1992, de 26 de marzo, de saneamiento de las aguas residuales en la Comunidad Valenciana (DOGV núm.1761, de 8 de abril); y el Decreto 266/1994, de 30 de diciembre, del Gobierno Valenciano por el que se aprueba el Reglamento sobre el régimen EconómicoFinanciero y Tributario del Canon de Saneamiento. (DOVG, núm.2418, de 31 de marzo). Para su aprovechamiento en riego, habría que destacar el Plan de Aprovechamiento y Distribución de Aguas Depuradas y Salinas (PAYDES), con la construcción de hasta 16 plantas en los años noventa. La entidad encargada de la gestión de las EDAR y del canon es la Entidad Pública de Saneamiento de Aguas Residuales de la Comunidad Valenciana (EPSAR), que en el ámbito alicantino de la DHS, en 2007, consiguió más de $20 \mathrm{hm}^{3}$ de reutilización. Un lustro después, el canon constaba de dos elementos: una parte fija anual y una parte variable según consumo, en municipios de más de 50.000 habitantes ascendía la llamada cuota de servicio a $36,85 €$ /año por usuario doméstico y a $0,352 €$ por metro cúbico consumido. 


\section{EVOLUCIÓN DEL APROVECHAMIENTO DE RETORNOS Y RESIDUALES EN LA CUENCA DEL SEGURA}

A lo largo de la historia del Segura se cuentan con noticias de aprovechamientos de retornos, así como de quejas por determinados vertidos que empeoraban la calidad del agua, especialmente para los usuarios de aguas abajo.

La red de riego tradicional está basada en la sucesión y escalonamiento de sistemas de azudes y acequias a lo largo del recorrido del río, desde el nacimiento en Pontones hasta la desembocadura en Guardamar. En la Vega Alta, hasta el enclave dónde se encuentra el Azud de La Contraparada, todas las colas o partes terminales de las acequias vierten al cauce del río, que ocupa la cota más baja del Valle fluvial, caracterizado por la sucesión de estrechos y cubetas en las que se ha desarrollado un rosario de huertas. En estos más de 250 kilómetros, por la pendiente y cota, recibe los retornos y efluentes que se producen a lo largo de este recorrido. Los retornos de riego y drenaje se mezclan e incorporan al caudal del Segura, así como algunos vertidos que en cierto modo se diluyen dando origen a un tipo de reutilización que se llama indirecta 5 .

Cuando el Segura se introduce en la Depresión Prelitoral, en la que recibe al Guadalentín o Sangonera, la pendiente es muy reducida, desde la Contraparada a Guardamar apenas salva sesenta metros en un recorrido de 85 kilómetros, por lo que meandriza sobre sus propios sedimentos. En este amplio valle, con puntos de más de 20 kilómetros de anchura, para establecer el regadío y desarrollar determinados cultivos que configuran la Huerta de Murcia, fue precisa la construcción de una doble red: La de azud y acequias, conocida como de aguas vivas, que derivan las aguas del río, y la de los azarbes, landronas y meranchos, conocida como de aguas muertas, que recogen a través de los escorredores todos los retornos de riego, así como determinados freáticos y vertidos, gracias a estar trazados por debajo del nivel de las acequias y el río, lo que permite captar aguas de reutilización para huertas aguas abajo, especialmente en la Vega Baja. El sistema se completaba con el acondicionamiento de los terrazgos mediante drenajes como los «embovedados» ${ }^{6}$.

$\mathrm{Al}$ ampliarse el valle del Segura y atenuarse las pendientes, al problema de los riegos se suman el del drenaje de las aguas infiltradas o excedentarias. Se hace necesario el desagüe, cuya red se creó al mismo tiempo que la de riego, originando un doble sistema de circulación del agua, cuya complejidad aumenta considerablemente al utilizarse como caudales de riego la que circula por los colectores que reciben «las expurgaciones, amarguras y salobres» de

5 «Esta forma de reutilización, que se puede llamar indirecta, se caracteriza porque el efluente se vierte a los cauces y se diluye con el propio caudal circulante, siendo utilizados ambos, de forma conjunta, aguas abajo. Es muy tradicional y practicada en la cuenca, y ha sido objeto de numerosos conflictos entre usuarios, y también de un completo tratamiento legal y administrativo...» (Ródenas, 2002: 115).

6 El sistema más sencillo de «dren» eran los manojos de cañas unidas por ladrillos perforados, situadas en zanjas de una profundidad de 40-50 $\mathrm{cm}$ en el suelo, y con una ligera pendiente hacia un escorredor a un azarbe menor. Los embovedados eran pequeños conductos subterráneos (permeables y de recorrido corto, con ligera pendiente a un escorredor o azarbe menor). La forma de construcción era la de realizar una apertura de zanja de 40-50 cm de profundidad sobre la que se depositaba una solera de grava, ladrillos macizos y tejas «morunas» usadas. Se cubrían esta semibóveda con piedra picada gruesa y se enrasaba de tierra la zanja al suelo del bancal. Por estos canalillos embovedados y permeables, escurría el exceso de agua que no captaban los cultivos en dirección a los escorredores y azarbes menores. 
la tierra (Canales, 2004: 441). En los $190 \mathrm{~km}^{2}$ de llanura aluvial de la Vega Baja del Segura, las aguas drenadas por los azarbes no se devuelven al río, si no que son reutilizadas para el riego. Esta red de azarbes permite mantener los niveles freáticos en cotas negativas, y así transformar áreas en cultivo que antes eran almarjales (en términos municipales como San Fulgencio, Dolores y San Felipe Neri). En las Ordenanzas del Juzgado Privativo de Aguas de Orihuela, en su artículo 10 figura: «hay otros acueductos llamados comúnmente de aguas muertas que sirven para recibir las expurgaciones, amarguras y salobres de las tierras...». Hay más de $180 \mathrm{~km}$ de conducciones de «aguas muertas» mediante escorredores, azarbes menores, y azarbes mayores.

Los retornos y vertidos empeoraban la calidad del agua, siendo a veces fuente de quejas de los vecinos situados aguas abajo, que deseaban usar el agua del río para abastecimiento y usos domésticos. Así ocurría con la suelta de las balsas dónde se preparaba el cáñamo, lino y, sobre todo el esparto. Posteriormente, el problema se fue agravando con los efluentes a cauce público de industrias papeleras, mataderos, conserveras, etc. de principios del siglo XX.

En el Archivo de la Confederación Hidrográfica del Segura (ACHS) en Santomera, en las llamadas Cajas de 1900 a 1941, se localizan varios escritos que refieren estas situaciones, así, en la Relación de Industriales que vierten las aguas residuales a cauce público, realizada en Molina de Segura por el Guarda Fluvial D. Jesús Marín, el 15 de julio de 1941, figuran: Mataderos de reses (Ayuntamiento de Molina y Ayuntamiento de Alguazas), el primero vertía al cauce del Segura, y el segundo al cauce del río Mula. Ocho fábricas de conservas en Molina de Segura que vertían a las acequia Suvirana y Mayor; cuatro en Lorquí que vertían a la Acequia Mayor, cinco en Alguazas que vertían al río Segura y al río Mula, y tres en Cotillas que vertían a la Acequia Mayor ${ }^{7}$.

En la obra de Mancha (1836), Memoria sobre la Población y los Riegos de la Huerta de Murcia, se describe la participación de riego de las aguas de los azarbes en los Heredamientos del Norte (Margen Izquierda del Segura) y del Mediodía (Margen derecha del Segura). Así en la Parte del Norte, para un total de riego de 47.076 tahúllas, unas 7.833 se regaban

7 En este último término de Cotillas, también se ha localizado en el ACHS, Cajas de 1900 a 1941, el escrito de 10 de noviembre de 1927 del entonces Alcalde-Presidente del Ayuntamiento de Las Torres de Cotillas D. Blas Martínez Bernal dirigido al Ministro de Fomento solicitando el auxilio público para el abastecimiento a través del proyectado Canal de la Mancomunidad. «Que siendo la más grave preocupación de este pueblo la carencia absoluta de aguas que sufre, no obstante estar limitado su término municipal por los ríos Segura y Mula, y soportar continuamente los gravísimos perjuicios ocasionados por las crecidas del primero que arrasan bancales, derrumban modestas viviendas de labradores y arrastran ganados, habiendo tenido que ser socorridos en varias ocasiones por el Gobierno de S. M. en vista de la tristísima situación en que quedaron numerosas familias, y no limitándose la escasez de tan preciado elemento al riego de su hermosa y extensa huerta, sino que también abarca el consumo público de su población de 3.511 habitantes de hecho. Los cuales para atender a sus necesidades domésticas han de acudir por el agua al punto más cercano del Río Segura que se halla a dos kilómetros del centro principal de la población, recogiéndolas la mayor parte de las veces turbias y cenagosas y en verano en que escasea el caudal de agua, contaminadas y en peligrosísimo estado para la salud pública...En este estado de cosas ha surgido el Real Decreto de 4 de Octubre último, relativo a los abastecimientos de aguas de la Base Naval de Cartagena, de esa misma población, de Murcia, Orihuela y algunas otras que solicitan asociarse a la Mancomunidad que en dicho Decreto se previene: y como quiera que al examinar el Proyecto de Canal de Conducción, éste pasa por el término municipal de Alcantarilla a ocho kilómetros aproximadamente de éste centro de población y a una altura de veinticinco metros sobre el nivel del mismo, lo cual hace suponer que de conseguir formar parte de la Mancomunidad y haciendo un esfuerzo económico el Municipio para hacer frente a las obras necesarias y cumplir las obligaciones que se imponga, se conseguiría ver realizada la aspiración suprema de este pueblo, dotándolo de un elemento de vida tan necesario como el agua...». 


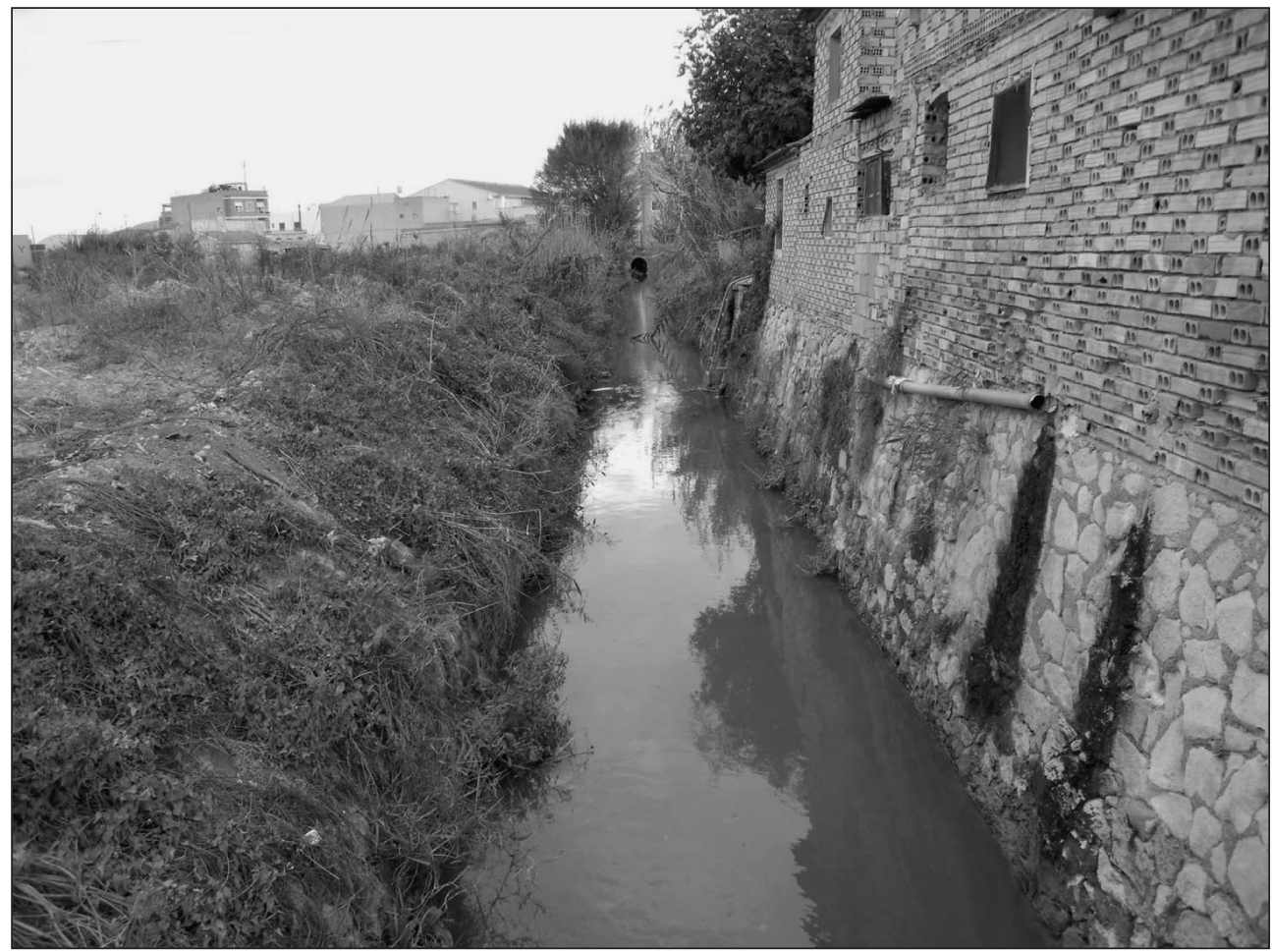

Fuente: Autores.

con cauces de aguas muertas como los Azarbes de Monteagudo, Mayor del Norte, etc., (el 16,64\% de la superficie regada). En la Parte del Mediodía para un total de 46.746 tahúllas, unas 12.105 se regaban con cauces de aguas muertas como los Azarbes de Beniel, El Riacho, etc., (el 25,90\% de la superficie regada) (Gómez, 2003: 38,41).

Mas reciente, en la adaptación de las Ordenanzas y Costumbres de la Huerta de Murcia a la Ley 29/1985 de Aguas figura, en el Capítulo II De los cauces de aguas vivas y muertas, la cuestión de la reutilización en los Art. $7^{\circ}$ y Art. $11^{\circ}$, en el Art. $7^{\circ}$ y se comenta lo siguiente: «Los cauces de aguas muertas sirven para recibir los avenamientos o escurrimbres de las tierras, descargándolas de la excesiva humedad que les perjudica. Éstos son los escorredores, las azarbetas y los azarbes o landronas. Los escorredores reciben los avenamientos de uno o de dos herederos; las azarbetas, de tres o más herederos, y los azarbes o landronas son los cauces en los que se reúnen dos o más azarbetas. También suelen llamarse meranchos o meranchones... Art. $11^{\circ}$ «Algunos de estos azarbes vienen luego a convertirse en acequias dando riego con sus aguas a otras tierras más bajas. Así se verifica en el Azarbe Mayor de la Ciudad, en el de Monteagudo, en el del Riacho y en el de Beniel» (Junta de Hacendados de la Huerta de Murcia, 2008, 15-16). 


\section{SITUACIÓN ACTUAL DEL APROVECHAMIENTO DE AGUAS RESIDUALES}

Los usos que se puedan dar a las aguas residuales tratadas en la DHS son varios: el mayoritario es la regeneración de las mismas y su aplicación al riego, le siguen en importancia los procesos de depuración para los llamados caudales ecológicos, al verter a cauce público una vez depuradas (uso ambiental), con al menos tratamiento primario y secundario y, finalmente, pero en menor volumen, es el caso de las que se reutilizan en el entorno de las industrias que los generan o en las urbanizaciones aplicadas a higiene de calles y riego de jardines. Siempre, en todos los casos, con los tratamientos necesarios para que garanticen la salud de los usuarios de estos espacios. Además hay que tener en cuenta el papel de los fangos y lodos para la agricultura y para la producción de biogás ${ }^{8}$.

\subsection{La importancia de las aguas residuales en los balances hídricos}

La reutilización de aguas residuales debe entenderse como un procedimiento planificado, con infraestructuras de distribución adecuadas y con normas rigurosas en el manejo del agua atendiendo a las exigencias de calidad de los usos implicados. La suma de estos requisitos motiva que sean pocas las regiones españolas que hacen uso de estos recursos no convencionales. Según estimaciones recogidas en el Plan Nacional de Calidad de las Aguas vigente, en la actualidad existen en España más de 2.500 EDAR que depuran más de 3.375 hm³ anuales de aguas residuales. De éstas, se estima que se reutilizan en la actualidad tan sólo unos 450 hm³/año, lo que supone un poco más del $13 \%$ del total; ello muestra el elevado potencial de esta tecnología para la generación de nuevos recursos hídricos, en un escenario futuro donde las perspectivas del cambio climático comportan una disponibilidad decreciente de recursos hídricos naturales. Según los últimos datos disponibles, la distribución por usos del agua depurada se sitúa en unas tres cuartas partes para uso agrícola, del orden del $12 \%$ para usos recreativos y campos de golf, el $6 \%$ para servicios urbanos, el $4 \%$ para usos ecológicos y recarga de acuíferos, y en torno al 3\% para uso industrial (MMA, 2007).

La reutilización de aguas residuales en las dos principales provincias (en términos superficiales) de la Demarcación Hidrográfica del Segura, Alicante y Murcia, ha experimentado diferentes grados de desarrollo: Alicante es una de las pioneras en España en este sentido, por ejemplo, desde 1980 se vienen elevando las aguas residuales de Alicante a los regadíos de uva de mesa embolsada del Medio Vinalopó, con un desnivel de 400 metros que es salvado mediante costosos bombeos. También se emplean aguas residuales en muchos municipios de la franja costera como sucede en el riego de los cultivos de nísperos de la Marina Baja, en los regadíos bajo plásticos de la antigua huerta de Alicante, de Elche, Torrevieja o el Pilar de la Horadada (Rico; 1998, 119). Sin embargo, el verdadero impulso en la difusión del tratamiento de las aguas residuales se produce con la aplicación del Plan Director de Saneamiento y Depuración de la Comunidad Valenciana, en cuyas primeras dos fases (1992-1996 y 1997-2005) se acometieron actuaciones que trataron de dar cobertura a aquellos municipios

8 El proceso de generación de fangos activos por aireación prolongada permite destinar los mencionados efluentes a las plantas de compostaje. Por su parte, en las EDAR con gran capacidad de tratamiento, el biogás derivado de esos lodos se quema para la producción de energía y reducir de esa manera el consumo energético de la propia instalación. 
con más de 2.000 habitantes. Aunque estas dos etapas iniciales no prestaron los réditos que cabría esperar de la inversión prevista, los esfuerzos realizados en los años posteriores han permitido mejorar sustancialmente el agua tratada de los $64 \mathrm{hm}^{3}$ en 1994, hasta los 134,13 $\mathrm{hm}^{3}$ de 2010, de los cuales se regeneraron mediante tratamiento terciario unos $93,03 \mathrm{hm}^{3}$ en las 146 EDAR instaladas (EPSAR, 2010). Las 29 EDAR de la Vega Baja, en el año 2012, trataron $22.081 .638 \mathrm{~m}^{3} / \mathrm{año}$.

El caso de la Región de Murcia resulta particularmente interesante pues se trata de una de las regiones que, en términos generales, ha registrado uno de los crecimientos más rápidos en materia de reutilización en comparación con el resto de autonomías españolas. Hasta la aprobación de la ley 3/2000 de Saneamiento y Depuración de Aguas Residuales de la Región de Murcia, los esfuerzos por parte de la administración autonómica se habían concentrado principalmente en el litoral de la comarca del Campo de Cartagena, a fin de mejorar la calidad de las aguas vertidas a la laguna del Mar Menor, zona catalogada «sensible» según contemplaba la Directiva Europea 91/271. Para ello se llevó a cabo la renovación de las redes de saneamiento y la construcción de dos grandes estaciones depuradoras, situadas al norte y sur del mar interior. Sin embargo, el resto del territorio murciano presentaba una situación hídrica ambiental crítica, por lo que resultaba imperativa la aprobación del Plan Regional para llevar a cabo los avances necesarios en la gestión del saneamiento y depuración de aguas residuales. Con la promulgación de esta norma se realizaron inversiones por un valor aproximado de 584 millones de euros hasta 2010 que se materializaron en el mantenimiento, sustitución y nueva construcción. Las 97 estaciones en funcionamiento (todos los núcleos de más de 500 habitantes contaban con una estación) trataron, para el mismo año, alrededor de unos 110,9 hm³/año, de los cuales, se regeneran más de la mitad. Los datos de 2012 manifiestan que se han reducido el número de EDAR, sin embargo, casi la totalidad de entidades poblacionales cuentan con depuración. De las gestionadas por ESAMUR, se trataron 109.406 .674 mªño, aumentando la proporción de la regeneración para riego.

En lo que se refiere al término administrativo de la DHS, las acciones desarrolladas anteriormente por las Administraciones, cada una en el ámbito de sus competencias, han producido un cambio sustancial consecuente con lo anteriormente comentado. En cifras generales, y a modo de balance, según la CHS, el abastecimiento de agua para consumo humano genera unos retornos de más del $80 \%$ del agua suministrada que son tratados por las EDAR de la Demarcación. Sin embargo, existen aún núcleos de población que por motivos generalmente asociados a su reducido tamaño o ubicación geográficamente dispersa, vierten sus aguas residuales directamente a cauces y suelos sin un tratamiento previo. De acuerdo con los datos disponibles, esto supone unos 7,5 hm³/año (según la información de las entidades del agua de Murcia y Alicante), no obstante, la aplicación de tecnologías más baratas y sencillas como el tratamiento simbiótico, reducirá en un futuro los pequeños núcleos sin depuración. En estas circunstancias, de un total de $189 \mathrm{hm}$ 3/año de aguas que se destinaban en 2010 a uso urbano e industrial, el volumen susceptible de ser tratado considerando que retorna el $80 \%$ del agua suministrada, sería de $151,2 \mathrm{hm} 3 /$ año. A esa cifra, habría que detraerle $7,5 \mathrm{hm}^{3} /$ año que no se tratan y $8,3 \mathrm{hm}^{3} /$ año que se pierden en el proceso, lo que da un caudal total de depuración de unos $135,4 \mathrm{hm}^{3} /$ año, de los cuales, $74,4 \mathrm{hm}^{3} /$ año se regeneraban y eran aptos para regadío. Cantidad nada desdeñable pero que todavía podría ampliarse, pues no hay que olvidar que, en 2012, el máximo susceptible de ser tratado se ampliaría al incluir las EDAR de Albacete 
y Almería, así como el montante de los regenerados para riego. En 2012, el caudal máximo regenerado concedido fue de $109.972 .596 \mathrm{~m}^{3} / \mathrm{año}$, ahora bien, el uso de las comunidades de regantes fue menor, ya que algunas de ellas no lograron recuperar de las EDAR esos volúmenes máximos concedidos por las CHS. En cualquier caso, la realidad del análisis realizado de los últimos años en lo que concierne al uso de los recursos regenerados para riego que verdaderamente se han aplicado a los perímetros regables en la Cuenca del Segura, se sitúan entre el 50 y $75 \%$ del tratado. La distribución geográfica de los mismos considerando las 155 concesiones de agua regeneradas para riego en la DHS (17/12/2013), es de: un 75,09\% a la Región de Murcia, el 19,06\% a Alicante (Vega Baja), el 4,00\% a Albacete, y el 0,95\% a Almería.

Tabla 1

VOLUMEN DE AGUA TRATADA Y REGENERADA EN LA DHS (MURCIA Y PARTE DE ALICANTE) AÑOS 2007 Y 2012 HM³/ $A N O$

\begin{tabular}{|c|c|c|c|}
\hline $\mathbf{2 0 0 7}$ & Tratada & Regenerada & Relación tratada/regenerada $(\boldsymbol{\%})$ \\
\hline Murcia & 101,00 & 45,6 & 45,14 \\
\hline Alicante & 27,00 & 20,2 & 74,81 \\
\hline TOTAL & 128,00 & 65,8 & 51,40 \\
\hline $\mathbf{2 0 1 2}$ & Tratada & Regenerada & Relación tratada/regenerada (\%) \\
\hline $\begin{array}{c}\text { Murcia } \\
\text { (ESAMUR) }\end{array}$ & 109,41 & 82,58 & 75,47 \\
\hline $\begin{array}{c}\text { Alicante } \\
\text { (EPSAR) }\end{array}$ & 22,08 & 21,95 & 99,41 \\
\hline TOTAL & 131,48 & 104,53 & 79,50 \\
\hline
\end{tabular}

Fuente: Elaboración propia a partir de datos del Estudio de Temas Importantes de la DHS para el 2007, y de ESAMUR y EPSAR para el 2012.

\subsection{La aplicación a riego de las aguas regeneradas según comunidades de regantes}

Una comunidad de regantes, es una corporación de Derecho Público, en la que los agricultores se agrupan con la finalidad de autogestionarse para distribuir el agua de un modo eficaz, ordenado y equitativo (Del Campo, 1996). Según la vigente Ley de Aguas (Ley 29/1985, de 2 de agosto y el Reglamento del Dominio Público Hidráulico, Real Decreto 849/86, de 11 de abril), se adopta el modelo de las comunidades de regantes (Real Orden de 25 de junio de 1884 del Ministerio de Fomento y Leyes de Aguas de 1866 y 1879), para todas las Comunidades de Usuarios. Por imperativo legal, los usuarios de aguas y otros bienes de dominio público hidráulico que disfrutan de una misma toma o concesión debían constituirse en Comunidad de Usuarios, y si el destino del agua era el riego, se denominaría Comunidad de Regantes.

En España existían, en 1994, casi 6.200 comunidades de regantes censadas (6.189 CC.RR. según el Catálogo General de las Comunidades de Regantes, elaborado por el Minis- 


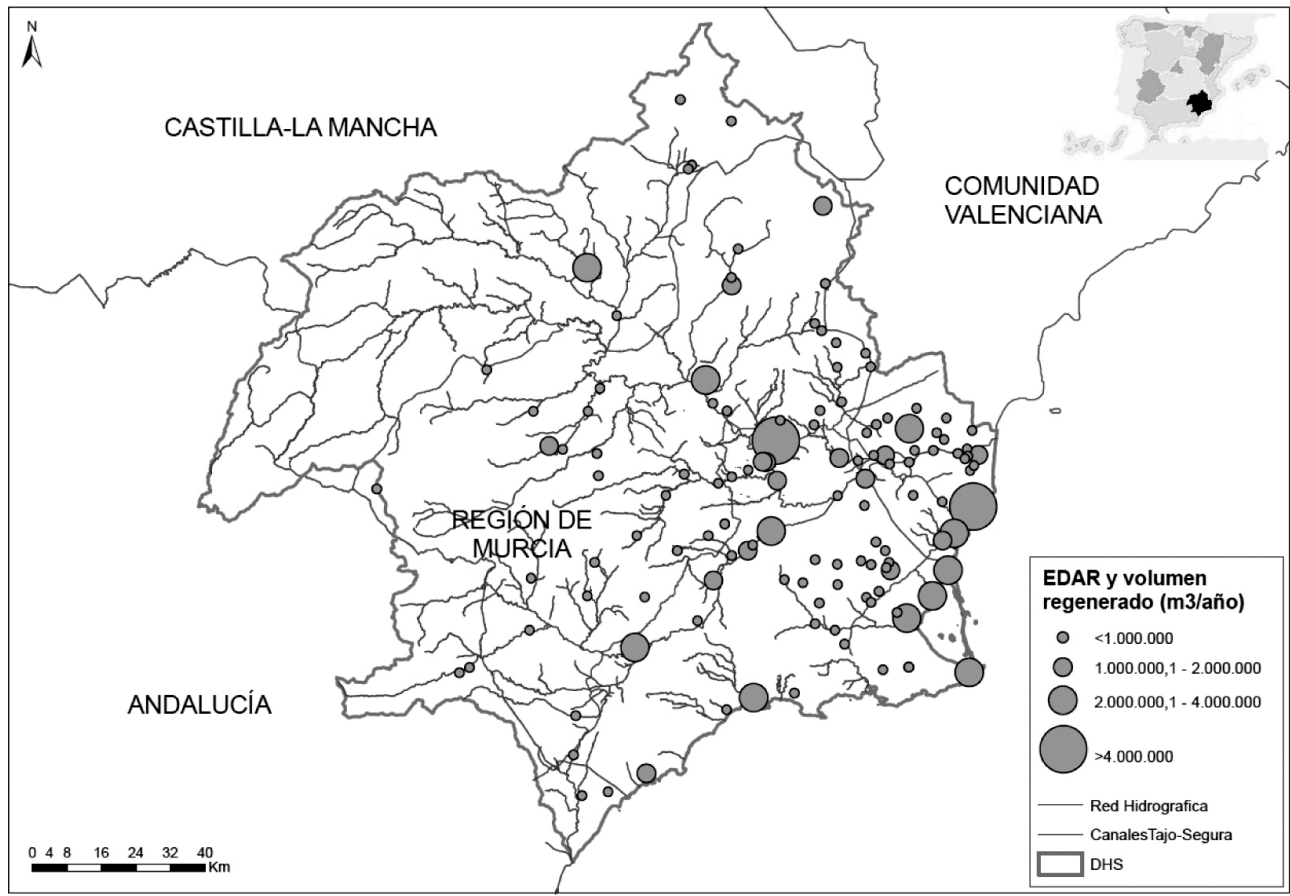

Fuente: Elaboración propia a partir de datos de la Comisaría de Aguas de la CHS (2012).

terio de Obras Públicas, Transportes y Medio Ambiente, en 1994). Y este Catálogo para la Cuenca del Segura nos proporcionaba unas 357 CC.RR., que reunían más de 133.025 hectáreas regadas.

En lo que se refiere al aprovechamiento de las aguas regeneradas con destino a regadío de las CC.RR. de la DHS, el balance deficitario de recursos de la cuenca convierte a los caudales de reutilización en un bien cada vez más preciado, principalmente, cuando se sabe que se trata de un recurso más o menos regular, y, de igual modo, no se encarezca de sobremanera el coste económico de regeneración y de la posterior impulsión, si fuese necesaria. Como se ha señalado con anterioridad, el destino de agua regenerada para riego se puede medir en función de las concesiones directas a las distintas comunidades de regantes. Este último valor ascendía en el año 2010 a 74,4 hm³/año, lo que enjuga un 4,47\% del total de la demanda agraria, evaluada para ese año en 1662 hm³/año.

Según la Comisaría de Aguas de la Confederación Hidrográfica del Segura, a 17 de abril de 2013, existían en la DHS 76 EDAR cuyas aguas tratadas se destinaban tras regeneración a riego; en beneficio, según concesiones, de 87 comunidades de regantes y sociedades agrarias de transformación.

Uno de los casos más interesantes de estas CC.RR., que se puede analizar dentro de la DHS, es la repercusión de estos caudales en la zona del Postrasvase. Este ámbito geográfico 
es cada vez más vulnerable en cuanto a su disponibilidad de agua. La situación que en los últimos años se está experimentando en cuanto a la llegada incierta de recursos procedentes del Tajo, hace volver la mirada de los agricultores hacia los caudales tratados por las EDAR, sobre todo, en situaciones de sequía o periodos de escasez hídrica. En este sentido, se ha realizado un balance hídrico de forma pormenorizada, empleando un estudio elaborado por investigadores de la Universidad de Córdoba, que precisa la demanda agraria de recursos hídricos necesarios para satisfacer a las masa de cultivos que en dicho espacio regularmente se producen (Ver Tabla 2).

Tabla 2

CONCESIONES DE AGUAS REGENERADAS EN REGADIOOS DEL POSTRASVASE TAJO-SEGURA

\begin{tabular}{|c|c|c|c|c|}
\hline Zona regable & $\begin{array}{l}\text { Superficie } \\
\text { cultivada } \\
\text { (ha) }\end{array}$ & 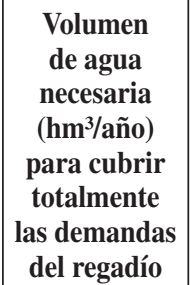 & $\begin{array}{l}\text { Concesiones } \\
\text { de aguas } \\
\text { regeneradas } \\
\left(\mathbf{h m}^{3} / \mathbf{a n ̃ o} \text { ) }\right.\end{array}$ & $\begin{array}{c}\% \text { de agua } \\
\text { demandada } \\
\text { cubierta } \\
\text { con aguas } \\
\text { regeneradas }\end{array}$ \\
\hline Campo de Cartagena & 31.160 & 181,26 & 13,446 & 7,4 \\
\hline Vegas Alta y Media I & 4.255 & 31,96 & 0,000 & 0,0 \\
\hline Vegas Alta y Media II & 3.469 & 35,27 & 0,450 & 1,3 \\
\hline Vegas Alta y Media III & 2.662 & 22,39 & 3,227 & 14,4 \\
\hline Vegas Alta y Media IV & 5.997 & 46,99 & 1,277 & 2,7 \\
\hline Vegas Alta y Media V & 4.147 & 37,37 & 0,000 & 0,0 \\
\hline Valle del Guadalentín Sector I ( Sangonera) & 2.280 & 16,37 & 1,500 & 9,2 \\
\hline V. Guadalentín Sector II (Librilla) & 2.537 & 23,97 & 0,232 & 1,0 \\
\hline V. Guadalentín Sectores III y IV (Alhama) & 3.838 & 29,66 & 0,884 & 3,0 \\
\hline V. Guadalentín Sectores V y VI (Totana) & 4.646 & 32,74 & 0,801 & 2,4 \\
\hline V. Guadalentín Sectores VII y VIII (Lorca) & 13.124 & 93,29 & 2,000 & 2,1 \\
\hline Mula, Yechar y La Puebla & 2.993 & 23,03 & 0,700 & 3,0 \\
\hline Riegos de Levante Margen Izquierda & 38190 & 216,06 & 1,498 & 0,7 \\
\hline Riegos de Levante Margen Derecha & 3.993 & 27,33 & 0,675 & 2,5 \\
\hline La Pedrera & 15.195 & 108,43 & 12,298 & 11,3 \\
\hline San Isidro y Realengo, Albatera & 1.500 & 10,14 & 0,601 & 5,9 \\
\hline Valle Almanzora & 3.000 & 20,48 & 0,130 & 0,6 \\
\hline TOTAL & 142.986 & 957 & 39,719 & 4,15 \\
\hline
\end{tabular}

Fuente: Elaboración propia a partir del Estudio sobre necesidades de agua de riego de los cultivos en la zona del Trasvase Tajo-Segura, realizado en el año 2006 por investigadores de la Univ. Córdoba para el SCRATS, y de las entrevistas realizadas a las Comunidades de Regantes en el año 2011 para el proyecto 12011/PHCS/09 de la Fundación Séneca por investigadores de la Univ. Murcia. 
De estas comunidades de regantes sobresale la del Campo de Cartagena que reutiliza unos 13,5 hm³/año procedentes de ocho EDAR (Gómez, López y Montaner, 2011: 302). Estos últimos recursos, junto a los del Trasvase Tajo-Segura, los de origen subterráneo y los de desalobración, han permitido a dicha comunidad situarse a la cabeza de la modernización de regadíos (Gil; 2010: 136).

En términos generales, tal y como se puede advertir en la tabla 3, el volumen de agua necesaria para cubrir las demandas del regadío de la zona del Postrasvase según los investigadores de la Universidad de Córdoba (2006) era de 957 hm³/año, una cantidad que se cubriría parcialmente con los $39,719 \mathrm{hm} 3 /$ año $(4,15 \%)$ que se regeneran en las EDAR.

La Orden de 18 de febrero de 2008, por la que se establecen las bases reguladoras de las ayudas para el aprovechamiento en regadío, de las aguas residuales regeneradas procedentes de las Estaciones Depuradoras de la Región de Murcia, expone en las disposiciones generales que si se viene haciendo un esfuerzo por aprovechar como recurso las aguas tratadas y regeneradas, es necesario facilitar a los usuarios-regantes de ellas los pasos para llevarlas desde las EDAR hasta las zonas de riego, en el marco de las actuaciones de mejora, consolidación y modernización de los regadíos.

Se han analizado las Comunidades de Regantes que han solicitado este tipo de ayuda, en la Región de Murcia (CARM), para realizar las obras necesarias con las que regenerar las aguas residuales concedidas y llevarlas a sus perímetros de riego y las hemos agrupado en la Tabla 3.

La ayuda a la mayor parte de estas comunidades fue de casi el 70\% de la inversión ejecutada, (casi el 60\% para la de «Costera Norte-Sierra de Carrascoy»), consistente la inversión en: entronques con las EDAR, arquetas de tomas, equipos de desinfección, estaciones de bombeo, tuberías de impulsión, automatismos, impermeabilización de lagos y embalses de regulación, estaciones de filtrado, arquetas de desagüe, conducciones, instalaciones eléctricas, etc.

Algunas de esas actuaciones relacionadas con el tratamiento del agua que las comunidades realizan, atienden al cumplimiento del RD 1620/2007, el cual establece los criterios de calidad exigidos para la reutilización de las aguas dependiendo del uso a que vayan a ser destinadas, en este caso, agrícola. Tal y como se advierte en la tabla 2, los tipos 3, 4 y 5 son los que verdaderamente cumplen con los requisitos para regadío y que en la actualidad solamente los suelen proporcionar aquellas EDAR que cuentan con tratamiento terciario, es decir un tipo de procedimiento formado por una coagulación-floculación, una decantación, una filtración y una desinfección. No obstante, como ya se ha dicho, existen casos en los que las concesiones que se otorgan a las Comunidades de Regantes que aprovechan estos recursos no convencionales, no alcanzan los niveles de los tipos exigidos por el RD 1620/2007, por lo que dichas entidades se ven obligadas a realizar la última fase de depuración bajo su responsabilidad y patrocinio.

\subsection{Otros usos de la reutilización}

Atendiendo a los datos de Comisaría de Aguas de la Confederación Hidrográfica del Segura, de las concesiones de aguas depuradas en la Región de Murcia, a la fecha de 17 de abril de 2013, se observa que varias EDAR de urbanizaciones, algunas del tipo residencial 
Tabla 3

AYUDAS PARA EL APROVECHAMIENTO EN REGADÍO DE AGUAS REGENERADAS PROCEDENTES DE LAS EDAR DE LAREGIÓN DE MURCIA

\begin{tabular}{|c|c|c|c|c|c|c|}
\hline Comunidades de Regantes & $\begin{array}{c}\text { Año de } \\
\text { Convoca- } \\
\text { toria }\end{array}$ & $\begin{array}{c}\mathbf{N}^{0} \text { de } \\
\text { Regantes }\end{array}$ & $\begin{array}{c}\text { Superficie } \\
\text { (ha) }\end{array}$ & EDAR & $\begin{array}{c}\text { Concesión } \\
\left(\mathbf{m}^{3} / \mathbf{a n ̃ o}\right)\end{array}$ & $\begin{array}{l}\text { Ayuda apro- } \\
\text { bada }(€)\end{array}$ \\
\hline S.A.T. «Los Rodeos-Mula» & 2008 & 109 & 461,59 & Ceutí y Lorquí & 2.077 .065 & $655.477,90$ \\
\hline C.R. «Puerto Lumbreras» & 2008 & 725 & $4.230,00$ & Puerto Lumbreras & 1.675 .000 & $447.415,08$ \\
\hline C.R. «Campo de Cartagena» & 2008 & 4821 & $41.294,00$ & $\begin{array}{c}\text { Fuente Álamo y } \\
\text { Torre Pacheco }\end{array}$ & 2.504 .000 & $464.827,92$ \\
\hline $\begin{array}{c}\text { C.R. «Heredamiento de } \\
\text { Aguas de la Puebla de Mula» }\end{array}$ & 2008 & 180 & 208,80 & Mula & 400.000 & $59.130,88$ \\
\hline C.R. «Campo Alto» & 2008 & 89 & 132,00 & La Paca (Lorca) & 60.155 & $179.022,20$ \\
\hline C.R. «Pozo de Santiago» & 2009 & 250 & $1.350,00$ & Yecla & 800.000 & $284.273,49$ \\
\hline C. R. «Arco Sur-Mar Menor» & 2010 & 149 & $1.528,00$ & Mar Menor-Sur & 4.864 .120 & $1.229 .827,30$ \\
\hline $\begin{array}{c}\text { C.R. «Costera Norte-Sierra de } \\
\text { Carrascoy» } \\
\end{array}$ & 2010 & 288 & $1.718,00$ & Alhama de Murcia & 297.906 & $85.663,79$ \\
\hline \begin{tabular}{|c|} 
C.R. «Hoya Mollidar-El Por- \\
tichuelo»
\end{tabular} & 2011 & 315 & $2.703,00$ & Yecla & 1.200 .000 & $718.447,10$ \\
\hline C.R. «Lorca» & 2011 & 8241 & $12.592,00$ & Lorca & 2.000 .000 & $488.950,00$ \\
\hline C.R. «Miraflores» & 2011 & 912 & $1.329,00$ & Jumilla & 1.500 .000 & $2.868 .985,00$ \\
\hline C.R. «Campo de Cartagena» & 2012 & 4820 & $11.421,00 *$ & Los Alcázares & 2.611 .141 & 1.665 .000 \\
\hline Totales & 2008-2012 & 20.899 & $78,967,39$ & Varias & 19.989.387 & $9.147 .020,66$ \\
\hline
\end{tabular}

* Sector de la CR Campo de Cartagena que recibe estas aguas. Fuente: Elaboración propia a partir de la Resolución de las Convocatorias de Ayudas de la Consejería de Agricultura y Agua de la CARM. (2008-2012).

«resort», contaban con depuración cuyo producto tratado se empleaba en el riego de los propios espacios verdes. Así sucede con las de Mosa Trayectum, Inmogolf Los Belones, Nova Cartago, Mar Menor Golf, etc. Algunas aguas depuradas de EDAR de industrias se aplican en el entorno rural de las mismas como Factoría El Pozo, en Alhama de Murcia; también ayuntamientos como el de Molina de Segura, que usaba una parte de las aguas tratadas de la EDAR Norte para el riego del parque urbano de «La Compañía».

Algunas vierten a cauce público, manteniendo un caudal ecológico. En la DHS, el caso más importante es el de la Depuradora de Murcia-Este en Rincón de Gallego (Llano de Brujas, Murcia), con más de $30 \mathrm{hm} 3 /$ año y un proyecto casi finalizado de elevar estas aguas depuradas hasta la altura de la Contraparada para así mantener un estado saludable del río a su paso por Murcia y su Huerta. Muñoz (2009: 80) señalaba que esta gran depuradora: «Se convertiría en el mejor pozo de sequía de la Vega Baja, por su aportación de más de $30 \mathrm{hm}^{3}$ ». En esta misma EDAR, en el año 2012, se puso en marcha un proyecto de cogeneración de 
Tabla 4

CRITERIOS DE CALIDAD PARA LA REUTILIZACIÓN DE AGUA RESIDUAL DEPURADA

\begin{tabular}{|c|c|c|c|c|c|c|}
\hline & \multirow[b]{3}{*}{ Usos del agua residual regenerada } & \multicolumn{5}{|c|}{ Criterios de calidad } \\
\hline & & \multicolumn{4}{|c|}{ Físico-químicos } & \multirow[b]{2}{*}{ Otros criterios } \\
\hline & & $\begin{array}{l}\text { Nemátodos } \\
\text { instenstinales }\end{array}$ & $\begin{array}{l}\text { E. coli } \\
\mathrm{ufc} / 100 \\
\mathrm{ml}\end{array}$ & $\begin{array}{l}\mathrm{MES} \\
\mathrm{mg} / \mathrm{L}\end{array}$ & Turbiedad & \\
\hline 1 & Residencial & $<1$ huevo/10L & 0 & $<10$ & $<2$ UNT & $\begin{array}{c}\text { Legionella spp. }<100 \\
\text { ucf } / \mathrm{L}\end{array}$ \\
\hline 2 & Servicios urbanos & $<1$ huevo/10L & $<200$ & $<20$ & $<10$ UNT & $\begin{array}{c}\text { Legionella spp. }<100 \\
\text { ucf } / \mathrm{L}\end{array}$ \\
\hline 3 & $\begin{array}{l}\text { Riego de cultivos con sistema de aplicación del agua } \\
\text { que permita el contacto directo del agua regenerada } \\
\text { con las partes comestibles para alimentación humana } \\
\text { en fresco }\end{array}$ & $<1$ huevo/10L & $<100$ & $<20$ & $<10$ UNT & $\begin{array}{l}\text { Legionella spp. }<1000 \\
\text { ucf } / \mathrm{L}\end{array}$ \\
\hline 4 & $\begin{array}{l}\text { Riego de productos para consumo humano con el } \\
\text { sistema de aplicación de agua que no evita el } \\
\text { contacto directo del agua regenerada con las partes } \\
\text { comestibles con consumo no fresco; riego de pastos } \\
\text { para consumo de animales productores de leche o } \\
\text { carne; acuicultura }\end{array}$ & $<1$ huevo/10L & $<1000$ & $<35$ & $\begin{array}{l}\text { No se fija } \\
\text { límite }\end{array}$ & $\begin{array}{l}\text { Taenia saginata y } \\
\text { Taenia solium }<1 \\
\text { huevo/L (si se riegan } \\
\text { pastos para consumo } \\
\quad \text { de animales } \\
\text { productores de carne) }\end{array}$ \\
\hline 5 & $\begin{array}{l}\text { Riego localizado de cultivos leñosos que impida el } \\
\text { contacto del agua regenerada con los frutos } \\
\text { consumidos en la alimentación humana; riego de } \\
\text { cultivos de flores ornamentales, viveros e } \\
\text { invernaderos sin contacto directo del agua } \\
\text { regenerada con las producciones; riego de cultivos } \\
\text { industriales no alimentarios, viveros, forrajes } \\
\text { ensilados, cereales y semillas oleaginosas }\end{array}$ & $<1$ huevo/10L & $<10000$ & $<35$ & $\begin{array}{l}\text { No se fija } \\
\text { límite }\end{array}$ & $\begin{array}{l}\text { Legionella spp. }<100 \\
\text { ucf } / \mathrm{L}\end{array}$ \\
\hline 6 & $\begin{array}{l}\text { Aguas de proceso de limpieza excepto en la industria } \\
\text { alimentaria; otros usos industriales }\end{array}$ & $\begin{array}{l}\text { No se fija } \\
\text { límite }\end{array}$ & $<10000$ & $<35$ & $<15$ & $\begin{array}{c}\text { Legionella spp. }<100 \\
\text { ucf/L }\end{array}$ \\
\hline 7 & $\begin{array}{l}\text { Aguas de proceso y limpieza para uso en la industria } \\
\text { alimentaria }\end{array}$ & $<1$ huevo/10L & $<10000$ & $<35$ & $\begin{array}{l}\text { No se fija } \\
\text { límite }\end{array}$ & $\begin{array}{c}\text { Legionella spp. }<100 \\
\text { ucf/L }\end{array}$ \\
\hline 8 & $\begin{array}{l}\text { Torres de refrigeración y condensadores } \\
\text { evaporativos }\end{array}$ & $<1$ huevo/10L & Ausencia & $<5$ & $<1$ & $\begin{array}{l}\text { Legionella spp. }<100 \\
\text { ucf } / \mathrm{L}\end{array}$ \\
\hline 9 & Riegos de campos de golf & $<1$ huevo/10L & $<200$ & $<20$ & $<10$ & $\begin{array}{c}\begin{array}{c}\text { Legionella spp. }<100 \\
\text { ucf } / \mathrm{L}\end{array} \\
\end{array}$ \\
\hline 10 & $\begin{array}{c}\text { Estanques, masas de agua y caudales circulantes } \\
\text { ornamentales, en los que está impedido el acceso al } \\
\text { agua }\end{array}$ & $\begin{array}{l}\text { No se fija } \\
\text { límite }\end{array}$ & $<10000$ & $<35$ & $\begin{array}{l}\text { No se fija } \\
\text { límite }\end{array}$ & $\operatorname{Pr}<2 \mathrm{mg} / \mathrm{L}$ \\
\hline 11 & $\begin{array}{l}\text { Recarga de acuíferos por percolación localizada a } \\
\text { través del terreno }\end{array}$ & $\begin{array}{c}\text { No se fija } \\
\text { límite }\end{array}$ & $<1000$ & $<35$ & $\begin{array}{l}\text { No se fija } \\
\text { límite }\end{array}$ & $\begin{array}{c}\mathrm{Nt}<10 \mathrm{mg} \mathrm{N} / \mathrm{L} \\
\mathrm{NO} 3<25 \mathrm{mg} \mathrm{NO} 3 / \mathrm{L}\end{array}$ \\
\hline 12 & Recarga de acuíferos por inyección directa & $<1$ huevo/10L & 0 & $<10$ & $<2$ UNT & $\begin{array}{c}\mathrm{Nt}<10 \mathrm{mg} \mathrm{N} / \mathrm{L} \\
\mathrm{NO} 3<25 \mathrm{mg} \mathrm{NO} 3 / \mathrm{L}\end{array}$ \\
\hline 13 & $\begin{array}{l}\text { Riego de bosques, zonas verdes y de otro tipo no } \\
\text { accesibles }\end{array}$ & $\begin{array}{l}\text { No se fija } \\
\text { limite }\end{array}$ & $\begin{array}{l}\text { No se fija } \\
\text { límite }\end{array}$ & $<35$ & $\begin{array}{l}\text { No se fija } \\
\text { límite }\end{array}$ & $\begin{array}{l}\text { Nitrógeno total }<50 \\
\mathrm{mg} / \mathrm{L}\end{array}$ \\
\hline 14 & Otros usos ambientales & La c & ad mínims & quer & se estudiar & caso por caso \\
\hline
\end{tabular}

Fuente: Ministerio de Medio Ambiente, 2007.

energía que produce toda la que se consume en todos los procesos de la planta e incluso excedentes que se venden a la red, como sucede con la ya mencionada de Molina de Segura.

En Campotejar (Molina de Segura, Región de Murcia), las viejas lagunas de la EDAR del núcleo urbano de Molina de Segura, han sido aprovechadas adecuándolas como embalses de acumulación de las aguas regeneradas de la nueva EDAR y se han convertido en humedales en el interior del territorio de la DHS, dentro de la red RAMSAR, y en los que se están desarrollando proyectos de investigación ambiental europeos sobre el hábitat de aves acuáticas 


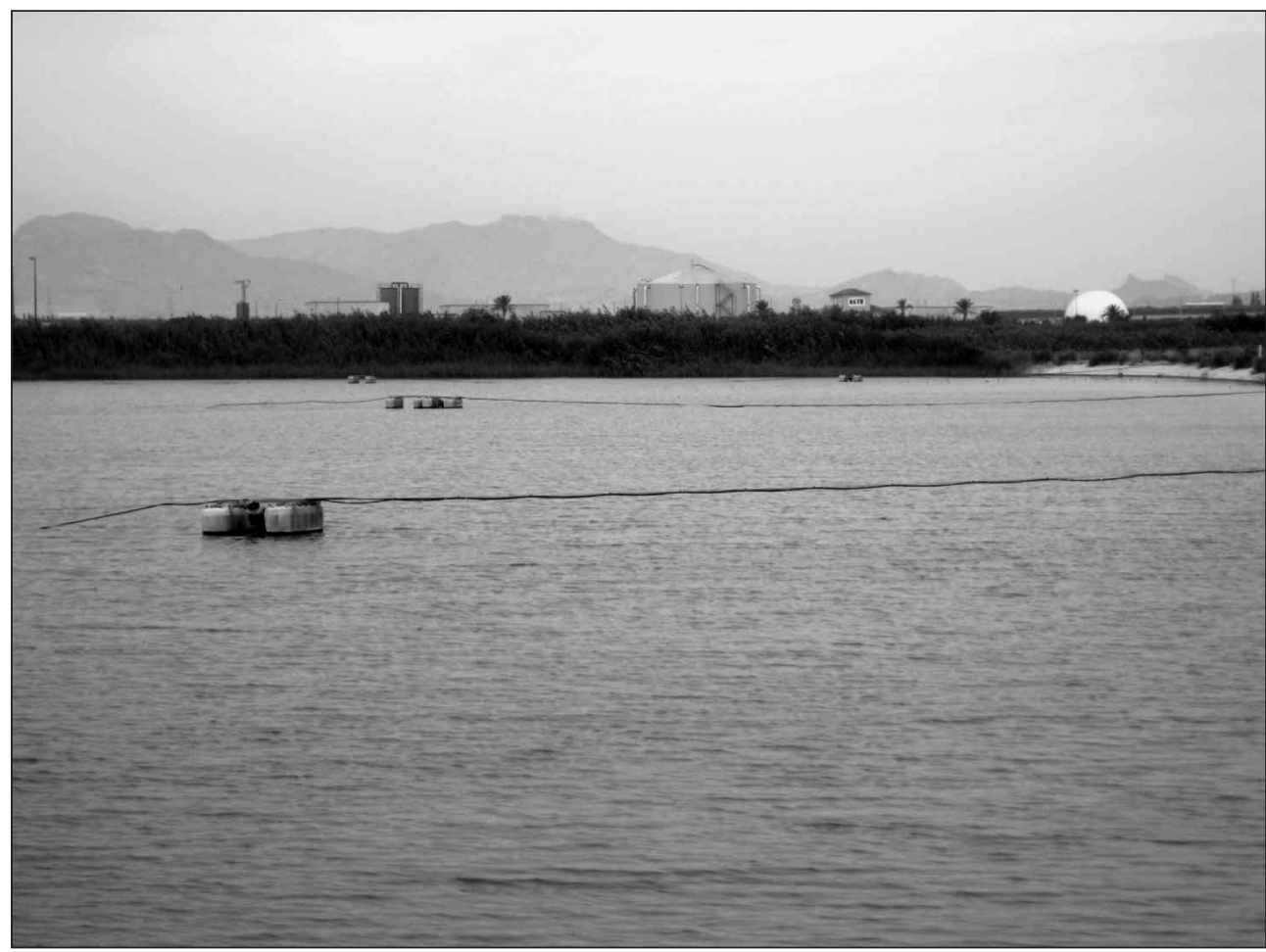

Fuente: Autores.

(entre otras anátidas como la Malvasía Cabeciblanca, Oxyura leucocephala). Un caso similar es el humedal de la desembocadura de la rambla de las Moreras en Mazarrón (Murcia), regenerado por el vertido del agua tratada de la EDAR y propuesto como sitio Ramsar, es decir, como Humedal de Importancia Internacional por reunir unos valores ecológicos singulares.

\section{CONCLUSIONES Y PROPUESTAS}

La Demarcación Hidrográfica del Segura (DHS), ubicada en el cuadrante suroriental de la Península Ibérica presenta un déficit hídrico estructural superior a los 300 hm³/año. En los últimos años, para cumplir con Directivas Comunitarias como la 91/271/CE y la 60/2000/ CE, se ha desarrollado el Plan Nacional de Calidad de las Aguas (2007-2015), y a nivel regional, la Ley 2/1992 de la Comunidad Valenciana, y la Ley 3/2000 de la Región de Murcia; cumpliéndose casi en su totalidad los objetivos previstos de saneamiento y depuración, así como la reutilización de estos caudales una vez depurados según el RD1620/2007.

El Plan de Saneamiento y Depuración de la Región de Murcia (2001-2010) parece haber cumplido con todas sus expectativas. De acuerdo a los datos consultados, las más 
de noventa EDAR en funcionamiento trataron en 2012 casi 110 hm³/año; el 99\% de la población cuenta con recogida y tratamiento de aguas residuales; la mayor parte de estos volúmenes recibían tratamiento biológico, y además, más de la mitad era sometido a tratamiento terciario de regeneración que incluye floculación físico-química, decantación terciaria, filtración, desinfección, cloración y, en algún caso, hasta ultrafiltración o microfiltración por membranas. Debido a lo anterior, la Región de Murcia recibió en el año 2012 el premio Acueducto de Segovia por la calidad de las infraestructuras que han participado (90 EDAR, 42 estaciones de bombeo y cientos de kilómetros de colectores). La gestión la realiza la Entidad de Saneamiento y Depuración de la Región de Murcia (ESAMUR), cuenta con la financiación del canon de saneamiento, que en el año 2012, ascendía (para usuario doméstico) la cuota de servicio a $32 € / a n ̃ o, ~ y ~ l a ~ d e ~ c o n s u m o ~ a ~ 0,27 € / \mathrm{m}^{3}$. En el caso de la Comunidad Valenciana (Infraestructuras de Saneamiento y Depuración de la parte de la provincia de Alicante que integra la DHS) era la Entidad Pública de Saneamiento de Aguas Residuales (EPSAR), y la cuota de servicio y de consumo ascendían a 36,85€/año y $0,352 € / \mathrm{m}^{3}$, respectivamente.

El volumen de agua tratada en la DHS se regeneraba más de la mitad, orientándose la mayor parte a redotar regadíos (hasta un máximo de $110 \mathrm{hm} 3 /$ año concedidos). El resto se destinaba a usos ambientales (caudal ecológico y creación de humedales en el interior de la DHS). Para estos aprovechamientos de reutilización son necesarias una serie de infraestructuras como: entronques con las EDAR, arquetas de tomas, estaciones de bombeo, tuberías para impulsión, estaciones de filtrado, impermeabilización de lagos y embalses, etc. Junto a la inversión privada, se ha necesitado de ayudas públicas, como las reflejadas en las Órdenes de Ayudas para Aprovechamiento en Regadío de las Aguas Residuales Regeneradas procedentes de las estaciones depuradoras de la Región de Murcia, convocadas por la Consejería de Agricultura y Agua de la CARM en los años 2008-2012.

Dentro de la DHS, apenas 10 hm³/año quedan por depurar, pero se reducirán con la introducción de tecnologías más baratas y eficientes que permitirán atender a los núcleos de menos de 500 habitantes e, incluso, a diseminados. Convenios de investigación, sobre tratamiento simbiótico como el llevado a cabo entre ESAMUR y la Universidad de Murcia contribuirán a aumentar el grado de satisfacción de depuración. Las experiencias de cogeneración como la de la nueva EDAR del municipio de Molina de Segura, la de Lorca, Alcantarilla y la de Murcia Este (todas en la Región de Murcia), reducirán los costes de tratamiento e, incluso, están capacitadas para el desarrollo de energías (biogás) a partir de fangos y residuos de los digestores anaerobios. El convenio firmado con el CEBAS-CSIC para la aplicación de fangos en suelos agrícolas tiene una importancia capital ya que en la Región de Murcia, en el 2010, se evacuaron 128,8 miles de Tm de fangos, el 93,9\% de ellos, aptos para su aplicación en la agricultura.

Finalmente, no hay que olvidar el valioso papel ambiental que estos caudales depurados juegan en forma de caudal ecológico en distintos tramos del Segura y su red de afluentes. Pero sobre todo, y lo más importante, gracias a estos recursos no convencionales, se está contribuyendo a reducir el déficit hídrico estructural de la DHS y a contar con dotaciones de agua fijas, incluso en aquellas situaciones en las que se produce una disminución acusada de las previsiones hídricas (bien sea por negativas al trasvase Tajo-Segura, sequías, etc.).

En definitiva, nos encontramos que en la DHS las inversiones públicas y privadas han generado una red de infraestructuras para la depuración y saneamiento de aguas residuales, 
así como para la reutilización, que la convierte en un modelo de aprovechamiento de estos recursos con una conciencia ciudadana que acepta el canon como necesario para mantener estas infraestructuras de depuración y saneamiento, y lograr retornos de calidad.

\section{FUENTES Y BIBLIOGRAFÍA}

\section{Fuentes}

A.C.H.S. (Santomera): Cajas de 1900 a 1941. Escrito de 10 de noviembre de 1927 del Excmo. Sr. Alcalde de Las Torres de Cotillas D. Blas Martínez Bernal al Ministro de Fomento, sobre los problemas de abastecimiento de agua de esta localidad.

A.C.H.S. (Santomera): Cajas de 1900 a 1941. Escrito de 15 de julio de 1941 del Guarda Fluvial D. Jesús Marín, sobre Relación de Industriales que vierten las aguas residuales a cauce público.

COMISARIA DE AGUAS de la C.H.S. Listado, de 2 de diciembre de 2011 y listado de 17 de abril de 2013 de las concesiones de aguas residuales otorgadas por este Organismo a las Comunidades de Regantes de la Cuenca del Segura.

DOCE (2000): Directiva 2000/60/CE del Parlamento Europeo y del Consejo de 23 de Octubre de 2000, por la que se establece un marco comunitario de actuación en el ámbito de la política de aguas. Diario Oficial de las Comunidades Europeas.

ESAMUR (marzo de 2011 y abril de 2013): Relación de EDAR gestionadas por ESAMUR, con el tipo de tratamiento y destino final de las aguas tratadas.

EPSAR (2010 y 2012): Relación de EDAR gestionadas por EPSAR, con el tipo de tratamiento y destino final de las aguas tratadas.

CONFEDERACIÓN HIDROGRÁFICA DEL SEGURA (2009). Tabla resumen de superficies, volúmenes y dotaciones (Trasvase y Cuenca) previstas para los usuarios del Trasvase Tajo-Segura tras la conclusión de la tramitación de concesiones del T.T.S.

CONSEJERÍA DE AGRICULTURA Y AGUA (CARM) (2008). Orden de 18 de febrero de 2008 , por la que se establecen las bases reguladoras de las ayudas para el aprovechamiento en regadío de las aguas residuales regeneradas procedentes de las Estaciones Depuradoras de la Región de Murcia. (BORM, nº 50, jueves, 28 de febrero de 2008).

MINISTERIO DE MEDIO AMBIENTE (2007). El Plan Nacional de Calidad de las Aguas: Saneamiento y Depuración 2007-2015.

MINISTERIO DE MEDIO AMBIENTE (2007). Real Decreto 1620/2007 por el que se establece el régimen jurídico de la reutilización de las aguas depuradas.

VILLALOBOS, J.; ORGAL, F.; FERRERES, E. (2006): Estudio sobre necesidades de agua de riego de los cultivos en la zona del Trasvase Tajo-Segura. Universidad de Córdoba. (Inédito).

\section{Bibliografía}

ALBACETE, M. (2009):»Regeneración de aguas residuales en la Región de Murcia«, en Jornadas sobre la Reutilización de aguas regeneradas: Cuestiones actuales y retos de futuro. Murcia, 1 y 2 de junio de 2009. 
ANGELAKIS AN, MARECOS DO MONTE MHF, BONTOUX L, ASANO, T. (1999): «The status of wastewaterreuse practice in the Mediterranean basin», en Water Res 33(10):2201-2217.

AYUSO, L.M.; CÁNOVAS, J.L.; LLORENS, M.; SÁEZ, J. (2008): «Depuración simbiótica. Una tecnología biológica para la depuración de aguas residuales del sector de conservas vegetales»en Revista Tecnología del Agua, Volumen 303, 48-54.

CANALES, G. (2004): «Avenamientos y utilización de aguas muertas» en La cultura del Agua en la Cuenca del Segura. Fundación CajaMurcia. Pp. 439-448.

DEL CAMPO, A. (1996): «Las Comunidades de Regantes: Historia, características, finalidad, y gestión», en XIV Congreso Nacional de Riegos. Aguadulce (Almería). Junio de 1996.

GIL, A. RICO, A.M. Y HERNÁNDEZ, M. (2005). «El trasvase Tajo-Segura». Observatorio medioambiental, (8), 073-110.

GIL, A. y RICO, A. (2007): El problema del agua en la Comunidad Valenciana. Fundación Agua y Progreso. Valencia.

GIL, E. (2010): «La Región de Murcia, un laboratorio de experiencias de ahorro y eficiencia en el uso del agua: la modernización de sus regadíos, entre las políticas agraria y ambiental de la Unión Europea», Papeles de Geografía, n 51-52, 131-146.

GIORGI, F., y LIONELLO, P. (2008): Climate change projections for the Mediterranean region. Global and Planetary Change, 63(2), 90-104.

GÓMEZ, M. (2008): Parámetros de control de los procesos de regeneración del agua. Universitat Politècnica de Catalunya. Departament d'Enginyeria Hidràulica, Marítima i Ambiental, Tesina en red (http://upcommons.upc.edu/pfc/handle/2099.1/6061) Fecha de consulta: 03/06/2013.

GÓMEZ, J.M.; LÓPEZ, J.A.; MONTANER, E. (Coord., 2011): Modernización de regadíos: Sostenibilidad social y económica. La singularidad de los regadios del Trasvase TajoSegura. Murcia. SCRATS, Universidad de Murcia (edit.um), Fundación Séneca.

GÓMEZ, J.M. (2003): «Rasgos socioeconómicos de la Memoria sobre la población y los riegos de la Huerta de Murcia» en La Población y los Riegos de la Huerta de Murcia de Rafael Mancha, 1836. Murcia. Tabularium. Edición Facsimilar, 29-44.

GUARDIA, E. (2013): «Pasado, presente y futuro en la gestión integral de aguas orientadas al riego de cultivos agrícolas: la desalación y reutilización como herramientas de apoyo sostenible al ciclo del agua» en PHICARIA. Encuentros internacionales del Mediterráneo, Murcia, 44-57.

JUNTA DE HACENDADOS DE LA HUERTA DE MURCIA (2008): Ordenanzas y Costumbres de la Huerta de Murcia 1849-2008. Murcia. Junta de Hacendados de la Huerta de Murcia.

MCCANAN, B. (2012): «Wastewater reuse brings life back to Spain's Segura river», Water 21, August 2012, London, 28-33.

MINISTERIO DE OBRAS PÚBLICAS, TRANSPORTES Y MEDIO AMBIENTE. (1994): Catálogo general de las comunidades de regantes. Madrid. Centro de Publicaciones del MOPTMA.

MUÑOZ, J. (2009): Contraparada. Murcia. Ingeniería 75, S.A. Junta de Hacendados de la Huerta de Murcia. 
NICOLÁS, E.; PEDRERO, F.; ALARCÓN, J.J.; MOUNZER, O.; MARTÍNEZ, V.; NORTES, P.A.; ALCÓN, F.; EGEA, G.; DE MIGUEL, M.D. (2012): Estudio de la viabilidad de uso de las aguas regeneradas procedentes de la EDAR de Jumilla en la Comunidad de Regantes Miraflores. Centro de Edafología y Biología Aplicada del Segura (CEBAS) y C.R. Miraflores, Cartagena, 55 pp.

OLLER RUBERT, M.; (2008): Perspectivas actuales en el saneamiento de las aguas residuales: gestión pública y privada. Castellón. Atelier.

PÉREZ, S.; KÖCK, M.; LEI TONG; GINEBREDA, A.; LÓPEZ-SERNA, R.; POSTIGO, C.; BRIX, R.; LÓPEZ DE ALDA, M.; PETROVIC, M.; WANG, Y. yBARCELO, D. (2011): «Wastewater Reuse in the Mediterranean Area of Catalonia, Spain: Case Study of Reuse of Tertiary Effluent from a Wastewater Treatment Plant at el Prat de Llobregat (Barcelona)» en D. Barcelo' and M. Petrovic (eds.) en Waste Water Treatment and Reuse in the Mediterranean Region, Hdb Env Chem.

REAL ACADEMIA DE LEGISLACIÓN Y JURISPRUDENCIA DE MURCIA (2001): La planificación hidrológica nacional y el déficit hídrico de la Cuenca del Segura. Murcia. Real Academia de Legislación y Jurisprudencia de Murcia.

RICO, A. (2006): «Políticas agrarias, eficiencia socioeconómica y retos de futuro de los regadíos intensivos», Boletín de la Asociación de Geógrafos Españoles, n 41, 113-149.

RICO, A.; OLCINA, J.; PAÑOS, V.; BAÑOS, C. (1998): Depuración, desalación y reutilización de aguas en España. Barcelona. Oikos-Tau.

RODENAS, M. A. (2002): «La reutilización del recurso» en La Confederación Hidrográfica del Segura 1926-2001. 75 Aniversario. Ministerio de Medio Ambiente. Confederación Hidrográfica del Segura. Murcia, 115-123.

SOLER, A.; BELCHI, R. y SÁEZ, J. (1995): «La depuración de aguas residuales en la Región de Murcia», Agua y Futuro en la Región de Murcia, Asamblea Regional de la Región de Murcia, 169-176. 
